\title{
Functional effect on implant overdentures according to modification of abutment height and attachment design
}

\author{
Richard Leesungbok * / Co-author; Su-Jin Ahn \\ * DMD, MSD, PhD. Head Prof. \& Chair, Dept of Biomaterials \& Prosthodontics, \\ Kyung Hee University Dental School Hospital at Gangdong, Seoul, Korea Republic of
}

\begin{abstract}
Stability, support and retention are very significant factors on implant overenture to increase patient satisfaction.

Many reports showed that magnetic attachment provides lower retention and stability of implant overdenuture than ball attachment and Locator attachment. But, Longitudinal clinical observations have revealed that the stability and comfort of the implant overdenture is more important to patient satisfaction.

Dental care and treatment, denture treatment are the most important issues for elderly people. Nevertheless within a limitation of the experiment, an abutment with increased height and a self-adjustable magnetic attachment provide significant higher stability and retention of implant overdentures. Patients' satisfaction is expected to be greater by increased retention and stability of implant overdenture.
\end{abstract}

\section{Background and Aim}

Background: Magnetic attachment provides lower retention and stability of implant overdenuture than ball attachment and Locator attachment. (Walid Sadig, 2009) Patients satisfaction and preference is higher bar clip and ball-sockets attachment than magnets attachment. This is related high stability than high bite force of implant overdenture. (Cune et al. 2005, Ellis et al 2009)

Aim: The aim of this study is to evaluate the influence according to modification of abutment height and attachment design on stability and retention of implant overdentures after releasing of directional loading force.

\section{Methods and Materials}

\begin{tabular}{|c|c|c|}
\hline & Attachment & \\
\hline NM3 & $\begin{array}{c}\text { 3mm height keeper abutment without } \\
\text { magnet (control group) }\end{array}$ & \\
\hline FM1 & $\begin{array}{c}1 \mathrm{~mm} \text { height keeper abutment } \\
+ \text { flat type magnetic attachment }\end{array}$ & \\
\hline FM3 & $\begin{array}{l}\text { 3mm height keeper abutment } \\
+ \text { flat type magnetic attachment }\end{array}$ & \\
\hline FM5 & $\begin{array}{l}\text { 5mm height keeper abutment } \\
+ \text { flat type magnetic attachment }\end{array}$ & 1 \\
\hline SM1 & $\begin{aligned} & 1 \mathrm{~mm} \text { height keeper abutment } \\
+ & \text { self-adjusting magnetic attachment }\end{aligned}$ & \\
\hline SM3 & $\begin{array}{c}\text { 3mm height keeper abutment } \\
+ \text { self-adjusting magnetic attachment }\end{array}$ & \\
\hline SM5 & $\begin{array}{c}5 \mathrm{~mm} \text { height keeper abutment } \\
+ \text { self-adjusting magnetic attachment }\end{array}$ & \\
\hline OR & O-ring attachment & 2 \\
\hline LO & Locator attachment & 3 \\
\hline
\end{tabular}

\section{Manufacturer ;}

1. AICHI STEEL, Aichi-ken, Japan

3. ZEST ANCHOR, CA92029, USA
Six groups were constructed with three different heights $(1 \mathrm{~mm}, 3 \mathrm{~mm}$, and $5 \mathrm{~mm})$ and two designs (flat type, self- adjustable type) of magnetic attachment. 2 groups were also constructed with two different attachments (O-ring, Locator). The control group had abutment of $3 \mathrm{~mm}$ in height without magnet. Total three tests were performed. 1) Stability test: 3D denture movement on a directional loading. 2) Retention test: Retention after releasing of directional $50 \mathrm{~N}$ loading. 3) Strain gauge analysis. Data were statistically analyzed using a 1-way ANOVA and between-group difference were analyzed with Tukey's post hoc test $(\alpha=0.05)$.
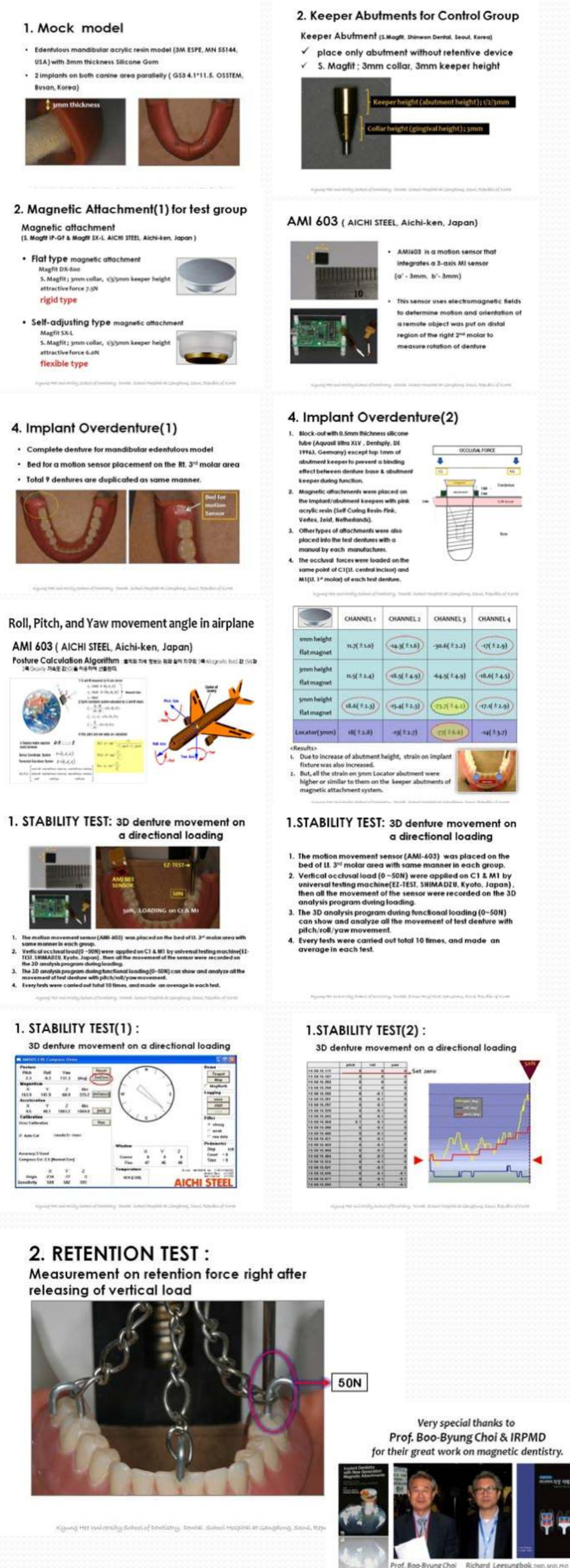

\section{Results}

Stability and retention were increased in relation to increasing the height of abutments. Self- adjustable type magnetic attachment had higher retention than flat type magnetic attachment after releasing of directional 50N loading. Strain around implants showed no significant difference between the selfadjustable magnetic attachment group with $5 \mathrm{~mm}$ abutment height and the Locator group $(\mathbf{p}<0.05)$

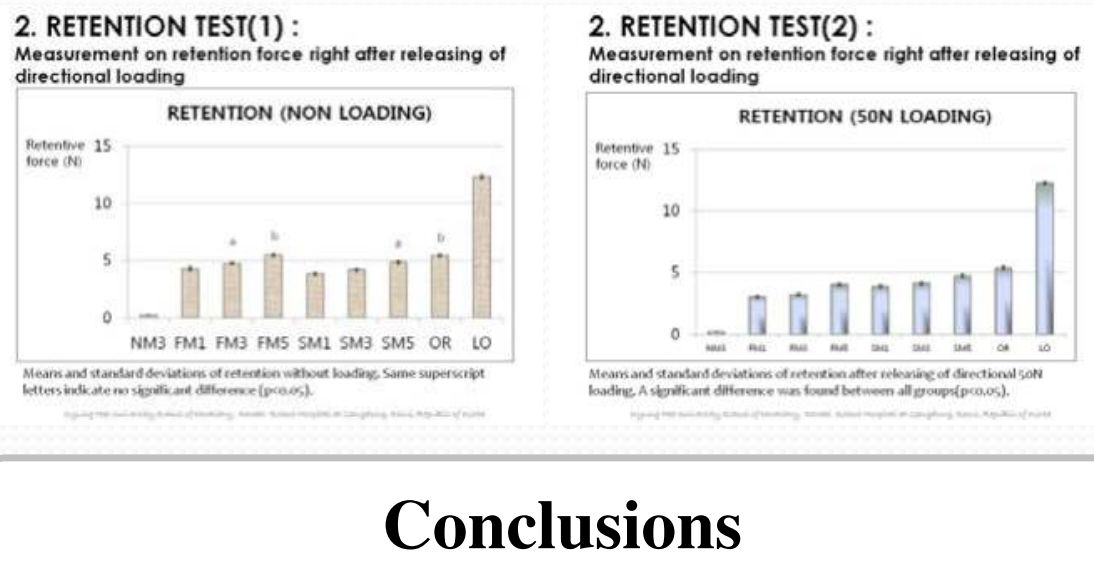

1. Stability and retention were increased according to the increasing height of magnetic attachment.

2. Self adjusting type magnetic attachment had higher retention than flat type magnetic attachment after releasing of directional 50N loading.

3. Strain around implants showed no significant difference between $5 \mathrm{~mm}$ height self-adjusting magnetic attachment group and Locator attachment group $(\mathbf{p}<0.05)$

4. The choice of the higher abutment and self adjusting type magnet provides significant higher stability and retention of implant overdenture. Patients' satisfaction is expected to be greater by increased retention and stability of implant overdenture.

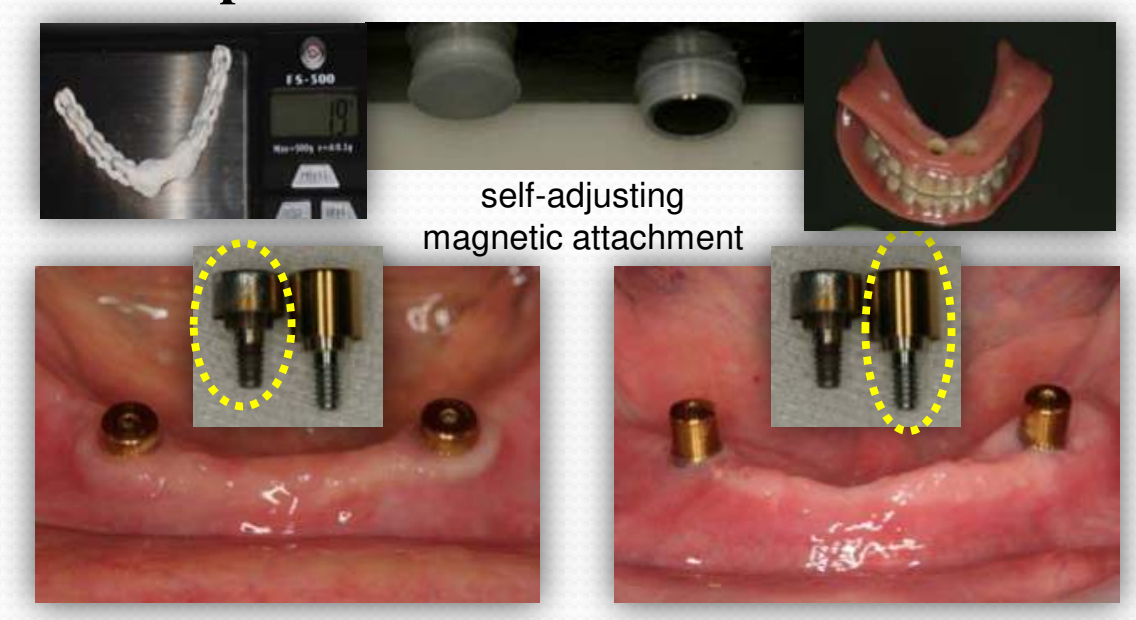

Considering that we are now entering into an aged society, dentures for the disabled and elderly play a crucial part in life satisfaction as well as heath related quality. Nutritional care is essential when they suffer from chronic and severe disorders. Patients' satisfaction is expected to be greater by increased retention and stability of implant overdentures.

\section{References \\ 1.Petropoulos VC, Smith W, Kousvelari E. Comparison of retention and release periods for implant overdenture attachments. Int J Oral
Maxillofac Implants 1997;12:176-85. 2.Walmsley AD. Magnetic retention in (2002:29:428-33. 3.Ellis JS, Burawi G, Walls A, Thomason JM. Patient satisfaction with two design of implant supported removable overdentures: ball attachment and}

